\title{
Rutting and moisture-induced damage potential of foamed warm mix asphalt (WMA) containing RAP
}

\author{
Mohammad Ashiqur Rahman ${ }^{1}$ (D) Rouzbeh Ghabchi $^{2} \cdot$ Musharraf Zaman $^{3} \cdot$ Syed Ashik Ali $^{4}$ (D)
}

Received: 5 February 2021 / Accepted: 24 April 2021 / Published online: 11 June 2021

(c) The Author(s) 2021

\begin{abstract}
Despite significant economic and environmental benefits, performance of warm mix asphalt (WMA) containing reclaimed asphalt pavement (RAP) remains a matter of concern. Among the current WMA technologies, the plant foaming technique (called "foamed WMA" in this study) has gained the most attention, since it eliminates the need for chemical additives. In the present study, the laboratory performance, namely rutting and moisture-induced damage potential of foamed WMA containing RAP were evaluated and compared with those of similar hot mix asphalt (HMA) containing identical amount of RAP. Dynamic modulus, Hamburg wheel tracking (HWT) and flow number tests were performed to assess the rutting resistance of the mixes. Also, stripping inflection point from HWT tests and tensile strength ratio after AASHTO T 283 and moisture induced sensitivity test (MIST) conditioning were used to evaluate the moisture-induced damage of asphalt mixes. It was found that MIST conditioning effectively simulates the moisture-induced damage and can capture the propensity of asphalt mixes to moisture damage more distinctly compared to AASHTO T 283 method due to application of cyclic loadings. The foamed WMA was found to exhibit higher rutting and moisture-induced damage potential due to lower mixing and compaction temperatures compared to HMA. However, the increase in RAP content was found to reduce rutting and moisture-induced damage potential for WMA. Therefore, the lower stiffness of foamed WMA may be compensated with the addition of stiffer binder from RAP.
\end{abstract}

Keywords Foamed warm mix asphalt (WMA) $\cdot$ Dynamic modulus $\cdot$ Rut depth $\cdot$ Stripping inflection point (SIP) $\cdot$ Tensile strength ratio (TSR)

\section{Introduction}

Construction of sustainable and environment-friendly transportation infrastructures results in saving natural resources, conserving the environment and reducing energy

This manuscript is a part of the corresponding author's MS thesis.

Mohammad Ashiqur Rahman

mohrahman@ucdavis.edu

Rouzbeh Ghabchi

Rouzbeh.Ghabchi@sdstate.edu

Musharraf Zaman

zaman@ou.edu

Syed Ashik Ali

syed.a.ali@ou.edu

1 School of Civil and Environmental Engineering, The University of California, Davis, One Shields Avenue, Davis, CA 95616, USA consumption [1,2]. For more than two decades, asphalt paving industry has been using reclaimed asphalt pavement (RAP) and various warm mix asphalt (WMA) technologies in the production of asphalt mixes and construction of flexible pavements as a part of efforts toward establishing a sustainable and eco-friendly construction practice [3-6].

2 Department of Civil and Environmental Engineering, South Dakota State University, 132 Crothers Engineering Hall, Brookings, SD 57007, USA

3 School of Civil Engineering and Environmental Science, Petroleum and Geological Engineering, The University of Oklahoma, 202 West Boyd Street, Room 334, Norman, OK 73019, USA

4 School of Civil Engineering and Environmental Science, The University of Oklahoma, 202 West Boyd Street, Room 334, Norman, OK 73019, USA 
The WMA technologies improve the workability of asphalt mixes using chemical additives, organic additives, and water-based or water-containing foaming processes [1, $2,7]$. These technologies reduce the mixing and compaction temperatures of traditional hot mix asphalt (HMA) by about $2-40{ }^{\circ} \mathrm{C}[8-10]$. Approximately $25-70 \%$ saving in energy consumption can be attained by lowering the mixing and compaction temperatures in WMA compared to HMA [11]. Among existing WMA technologies, plant foaming (called "foamed WMA" in this study) is being successfully used for production of asphalt mixes. This technique makes the foamed WMA more cost effective, since no chemical WMA additive is needed. Also, the utilization of RAP in asphalt mixes has increased rapidly due to its economic and environmental benefits [12]. The availability of binder in RAP reduces the amount of virgin binder needed in producing asphalt mixes. Furthermore, the aggregates in the RAP are reused to lower initial construction costs and preserve natural resources $[12,13]$. However, incorporation of RAP in asphalt mixes has introduced many challenges, such as change in binder performance grade (PG) due to the addition of stiffer binder from RAP, uncertainty in blending between virgin and aged binder, high amount of filler materials, quality of RAP, and lack of performance data $[12,13]$. Therefore, the laboratory performance of WMA containing RAP is still a matter of concern.

According to Bonaquist [1], the volumetric properties of foamed WMA may be similar to those of HMA, when other parameters (aggregate gradation, binder content, number of gyrations and RAP content) remain constant. However, the laboratory performance specially, rutting resistance and moisture-induced damage potential of foamed WMA can be significantly different from HMA [1, 5, 14, 15]. Also, these characteristics become more complex with the addition of high percentage of RAP in asphalt mixes $[3,4,14,16]$.

Reduced aging of foamed WMA due to lower mixing temperature is known to produce softer mixes compared to HMA [7, 17, 18]. Aged binder from RAP, on the other hand, makes asphalt mixes stiffer $[3,4,6,16,19]$. A stiffer mix is expected to exhibit more resistance to permanent deformation or rutting $[4,6,9]$. It is believed that the stiff and aged binder from RAP would counteract with the softer WMA mix to balance the rutting resistance of WMA [18]. Another concern for WMA is the partially dried aggregates which can result from lower mixing and compaction temperatures $[9,17,20]$. Also, injection of water during the foaming process can result in higher susceptibility to moisture-induced damage for foamed WMA mixes [21]. On the contrary, the stronger bond in the RAP binder and aggregate may counteract the moisture-induced damage potential of foamed WMA $[5,14,15]$. Although there is a need for studying the effects of using foamed WMA and RAP in asphalt mixes on their performance, the knowledge about laboratory performance of foamed WMA containing RAP, particularly when high amount of RAP is used, is limited. Therefore, the present study was undertaken to examine the rutting and moistureinduced damage performances of foamed WMA containing RAP compared to those of similar HMA.

\section{Materials and methods}

\section{Materials}

Two types of aggregate gradations, with nominal maximum aggregate sizes (NMAS) of 19.0 and $12.5 \mathrm{~mm}$ were used for production of asphalt mixes. The asphalt mixes having a NMAS of $19.0 \mathrm{~mm}$ (i.e., S3 mixes) were designed and prepared with 25\% RAP. The asphalt mixes having a NMAS of $12.5 \mathrm{~mm}$ (i.e., $\mathrm{S} 4$ mixes) contained 5\% RAP. The amount of RAP in mixes was selected in accordance with the current Oklahoma Department of Transportation (ODOT) specifications (ODOT, 2013). A PG 64-22 asphalt binder was used as the virgin binder in producing the HMA. From the viscosity-temperature relationship of the asphalt binder, the mixing and compaction temperatures for HMA were used as 163 ${ }^{\circ} \mathrm{C}$ and $149^{\circ} \mathrm{C}$, respectively [22]. To produce WMA, the collected PG 64-22 binder was foamed using $2 \%$ foaming agent (water) by the weight of asphalt binder using a laboratory foamer, Accufoamer ${ }^{\circledR}$ from Instrotek. The mixing and compaction of foamed WMA were performed at $135^{\circ} \mathrm{C}$ and 127 ${ }^{\circ} \mathrm{C}$, respectively. These temperatures were selected based on the previous studies conducted on foamed WMA technology and the current practice used by the local asphalt producers $[1,18]$. In this study, a total of four asphalt mixes (two HMA and two foamed WMA) were produced in the laboratory. HMA S3 and WMA S3 were prepared using S3 aggregate gradation with an optimum binder content of $4.5 \%$, whereas HMA S4 and WMA S4 were prepared using S4 aggregate gradation with $4.9 \%$ optimum binder content. The HMA S3 and HMA S4 were prepared using the HMA mix design procedure at higher mixing $\left(163^{\circ} \mathrm{C}\right)$ and compaction $\left(149^{\circ} \mathrm{C}\right)$ temperatures without foamed binder and were considered as control mixes. On the other hand, the WMA S3 and WMA $\mathrm{S} 4$ were produced at WMA mixing $\left(135^{\circ} \mathrm{C}\right)$ and compaction $\left(127^{\circ} \mathrm{C}\right)$ temperatures using the foamed binder. The details of these four mixes are given in Table 1.

\section{Sample preparation}

Asphalt samples for all performance tests were prepared in the laboratory using a Superpave ${ }^{\circledR}$ Gyratory Compactor (SGC). After mixing, bulk HMA was short-term aged at $135^{\circ} \mathrm{C}$ for $4 \mathrm{~h}$ as per AASHTO R 30 in order to simulate the conditioning of plant-produced mixes [22]. As suggested by Bonaquist [1], the bulk WMA was short-term 
Table 1 Properties of the asphalt mixes

\begin{tabular}{llllllll}
\hline Mix ID & Mix type & $\begin{array}{l}\text { Optimum binder } \\
\text { content }(\%)\end{array}$ & $\begin{array}{l}\text { Mixing/compaction } \\
\text { temperatures }\left({ }^{\circ} \mathrm{C}\right)\end{array}$ & NMAS (mm) & Binder type & $\begin{array}{c}\text { Foamed binder } \\
\text { Absorbed } \\
\text { binder }(\%)\end{array}$ & $\begin{array}{l}\text { RAP } \\
\text { content } \\
(\%)\end{array}$ \\
\hline HMA S3 & HMA & 4.5 & $163 / 149$ & 19 & PG 64-22 & No & 0.42 \\
WMA S3 & WMA & 4.5 & $135 / 127$ & 19 & PG 64-22 & Yes & 0.42 \\
HMA S4 & HMA & 4.9 & $163 / 149$ & 12 & PG 64-22 & No & 0.46 \\
WMA S4 & WMA & 4.9 & $135 / 127$ & 12 & PG 64-22 & Yes & 0.46 \\
\hline
\end{tabular}

aged at WMA compaction temperature $\left(127^{\circ} \mathrm{C}\right)$ for $2 \mathrm{~h}$ to simulate the conditioning of WMA plant-produced mixes. After the compaction, volumetric tests were conducted to check air voids in accordance with AASHTO T 166 [22]. The target air voids were kept at $7 \pm 0.5 \%$ based on the densities typically obtained in the field [22].

\section{Laboratory tests}

\section{Dynamic modulus (DM) test}

Dynamic modulus tests were conducted as per AASHTO T 378 using an asphalt mixture performance tester (AMPT) [22]. For this purpose, over-size samples with a diameter of $150 \mathrm{~mm}$ and a height of $167.5 \mathrm{~mm}$ were prepared using SGC. These samples were then cored from the center to obtain specimens having a diameter of $100 \mathrm{~mm}$. The cored specimens were cut at both ends using a heavy duty saw to obtain specimens with a height of $150 \mathrm{~mm}$. As suggested by Chehab [23], this method produces specimen with uniform air voids in both vertical and radial directions. For each asphalt mix, three replicates were prepared for dynamic modulus testing.

The dynamic modulus tests were conducted at four different temperatures, namely $4.4,21.1,37.8$, and $54.4^{\circ} \mathrm{C}$. For each temperature, six different loading frequencies, namely $25,10,5,1,0.5$ and $0.1 \mathrm{~Hz}$ were used. The applied loading consisted of a sinusoidal compressive (haversineshaped) pulse. The load magnitude was adjusted based on the material stiffness, frequency and temperature, to keep the strain response within 50-150 micro-strains. Although dynamic modulus tests can be performed under both confined and unconfined conditions, unconfined condition was used here [22]. Finally, a master curve was developed at a reference temperature of $21.1{ }^{\circ} \mathrm{C}$ using the time-temperature superposition principal. A sigmoidal function was used in fitting the master curve [24]. Details of the time-temperature superposition method can be found in Singh [24].

\section{Hamburg wheel tracking (HWT) test}

The HWT test was conducted in accordance with AASHTO T 324 to determine the rutting susceptibility and moistureinduced damage potential of the aforementioned mixes [22]. Cylindrical samples with a diameter of $150 \mathrm{~mm}$ and a height of $60 \mathrm{~mm}$ were prepared in the laboratory. The HWT tests were conducted at $50{ }^{\circ} \mathrm{C}$ with a frequency of 52 wheel passes/minute and a wheel load of $705 \mathrm{~N}$. The test was automatically terminated after reaching a maximum rut depth of $20 \mathrm{~mm}$ or 20,000 wheel passes, whichever reached first. The HWT test results were analyzed using both conventional and the method proposed by Yin et al. [25].

In the conventional analysis of HWT test results, the post-compaction deformation, creep slope, stripping slope, and stripping inflection point (SIP) were determined manually. The initial densification of asphalt pavement due to the movement of traffic is indicated by the post-compaction deformation. Yildirim and Kennedy [26] suggested the rut depth at 1000 wheel passes as the post-compaction point. After post-compaction zone, the rut depth increases linearly with the number of wheel passes up to certain point. The slope of this zone is commonly known as creep slope. After that, a rapid increase in rut depth was observed with the increase in wheel passes. This rapid deformation of HWT sample is attributed to tertiary deformation. The slope of this tertiary zone is commonly known as stripping slope. The moisture-induced damage potential of asphalt mixes is measured by this stripping slope. The intersection between the stripping slope and creep slope is represented by the SIP. The SIP can be defined as the number of repeated load cycles after which an abrupt increase in rut depth is observed in the HWT test due to stripping of binder from the aggregate [27].

In addition to conventional analysis, HWT test results were analyzed using the method proposed by Yin et al. [25]. This method is expected to differentiate the stripping strain from the visco-plastic strain using the curve fitting equations. Three parameters, namely, stripping number $\left(\mathrm{LC}_{\mathrm{SN}}\right)$, stripping life $\left(\mathrm{LC}_{\mathrm{ST}}\right)$ and viscoelastic strain increment $\left(\Delta \varepsilon_{10,000}^{v p}\right)$ were proposed by Yin et al. 
[25] to evaluate the rutting and moisture-induced damage potential of asphalt mixes [25]. In this method, the wheel passes at which stripping starts is represented by the stripping number $\left(\mathrm{LC}_{\mathrm{SN}}\right)$. After $\mathrm{LC}_{\mathrm{SN}}$, the additional wheel passes required for stripping strain to result in $12.5 \mathrm{~mm}$ rut depth is represented by stripping life $\left(\mathrm{LC}_{\mathrm{ST}}\right)$. Therefore, the moisture-induced damage potential before and after the stripping is evaluated by $\mathrm{LC}_{\mathrm{SN}}$ and $\mathrm{LC}_{\mathrm{ST}}$, respectively. A higher moisture-induced damage potential of asphalt mixes is represented by the lower $\mathrm{LC}_{\mathrm{SN}}$ and $\mathrm{LC}_{\mathrm{ST}}$ values. Also, in this method, $\Delta \varepsilon_{10,000}^{v p}$ indicates the resistance to rutting before stripping occurs. In this method, the projected visco-plastic strain increment till 10,000 wheel passes is used as $\Delta \varepsilon_{10,000}^{v p}$. The asphalt mixes with lower $\Delta \varepsilon_{10,000}^{v p}$ values are expected to show higher rutting resistance.

\section{Flow number (FN) test}

The FN test was conducted according to AASHTO T 378 using an AMPT [22]. The FN is defined as the number of load cycles related to the minimum rate of change in permanent axial strain in a repeated loading test of asphalt specimen [28]. In this study, the flow number test was conducted on the same specimen used for dynamic modulus test, because the specimen was not loaded beyond the elastic range in dynamic modulus test [22]. The FN test specimens were subjected to a $0.1 \mathrm{~s}$ repeated haversine axial compressive loading pulse followed by a $0.9 \mathrm{~s}$ of rest period. The test was conducted at unconfined state with a contact stress of $30 \mathrm{kPa}$ and repeated axial stress of $600 \mathrm{kPa}$. All the tests were conducted at $64{ }^{\circ} \mathrm{C}$, which was selected based on the high-temperature PG of the selected binder. The FN test was continued up to 10,000 loading cycles or until excessive tertiary deformation observed on the specimen.

\section{Indirect tensile strength ratio (TSR) test}

Several researchers have used tensile strength ratio (TSR) as a potential indicator of moisture-induced damage $[5,29,30]$. It represents the indirect tensile strength ratio of moistureconditioned and dry samples. In this study, samples were conditioned following both AASHTO T 283 and moisture induced sensitivity test (MIST) methods to determine the TSR values. For each mix, three replicates of cylindrical sample having a diameter of $150 \mathrm{~mm}$ and a height of $115 \pm 5$ $\mathrm{mm}$ were prepared in the laboratory using SGC. The indirect tensile strength (ITS) tests were conducted on both dry and moisture-conditioned asphalt samples at $25{ }^{\circ} \mathrm{C}$. The tests were conducted according to ASTM D 6931 [31]. Equation (1) was used to calculate the TSR value.
$\mathrm{TSR}=\frac{\text { ITS of Moisture }- \text { conditioned Samples }\left(\text { ITS }_{\mathrm{F}-\mathrm{T} / \mathrm{MIST}}\right)}{\text { ITS of Dry }- \text { conditioned Samples }\left(\text { ITS }_{\mathrm{dry}}\right)}$

\section{Moisture conditioning of compacted samples}

\section{AASHTO T 283 method}

The AASHTO T 283 method, commonly known as freeze-thaw method, was used for simulating the moistureinduced damage in the compacted samples before conducting ITS test [22]. According to this procedure, samples were conditioned by saturating with water (70-80\% saturation), followed by a freezing cycle $\left(-18{ }^{\circ} \mathrm{C}\right.$ for $\left.16 \mathrm{~h}\right)$ and a thawing cycle $\left(60^{\circ} \mathrm{C}\right.$ water bath for $\left.24 \mathrm{~h}\right)$. The weathering effect on the asphalt sample was simulated by this conditioning method [22].

\section{Moisture induced sensitivity test (MIST) conditioning}

MIST is relatively a new technique to simulate the generation and dissipation of pore water pressure in a saturated asphalt pavement. Initially, the TSR samples were conditioned at $60{ }^{\circ} \mathrm{C}$ for $20 \mathrm{~h}$ in water to simulate chemical and adhesion effects [31]. After the adhesion phase, samples were subjected to 3500 pressure cycles at $280 \mathrm{kPa}$ to generate the effect of pore pressure buildup inside the sample according to ASTM D 7870 [31].

\section{Results and discussion}

\section{Rutting performance}

\section{Dynamic modulus test}

Figure $1 \mathrm{a}, \mathrm{b}$ represents the dynamic modulus master curve at $21.1{ }^{\circ} \mathrm{C}$ temperature for S3 mixes (HMA S3 and WMA S3) and S4 mixes (HMA S4 and WMA S4), respectively. An increase in dynamic modulus values was observed with an increase in frequency and decrease in testing temperature. These results are compatible with expectations as an increase in testing frequency and/or a decrease in temperature increases the stiffness of asphalt mixes [13, 24, 32].

Also, both HMA and foamed WMA showed a similar trend in the dynamic modulus master curve (Fig. 1). However, relatively lower dynamic modulus values were observed for foamed WMA (WMA S3 and WMA S4) than HMA (HMA S3 and HMA S4). For example, at $10^{-4} \mathrm{~Hz}$ reduced frequency, predicted dynamic modulus values for HMA S3 and WMA S3 were $249 \mathrm{MPa}$ and $147 \mathrm{MPa}$, respectively. A similar trend was observed for $\mathrm{S} 4$ mixes. 

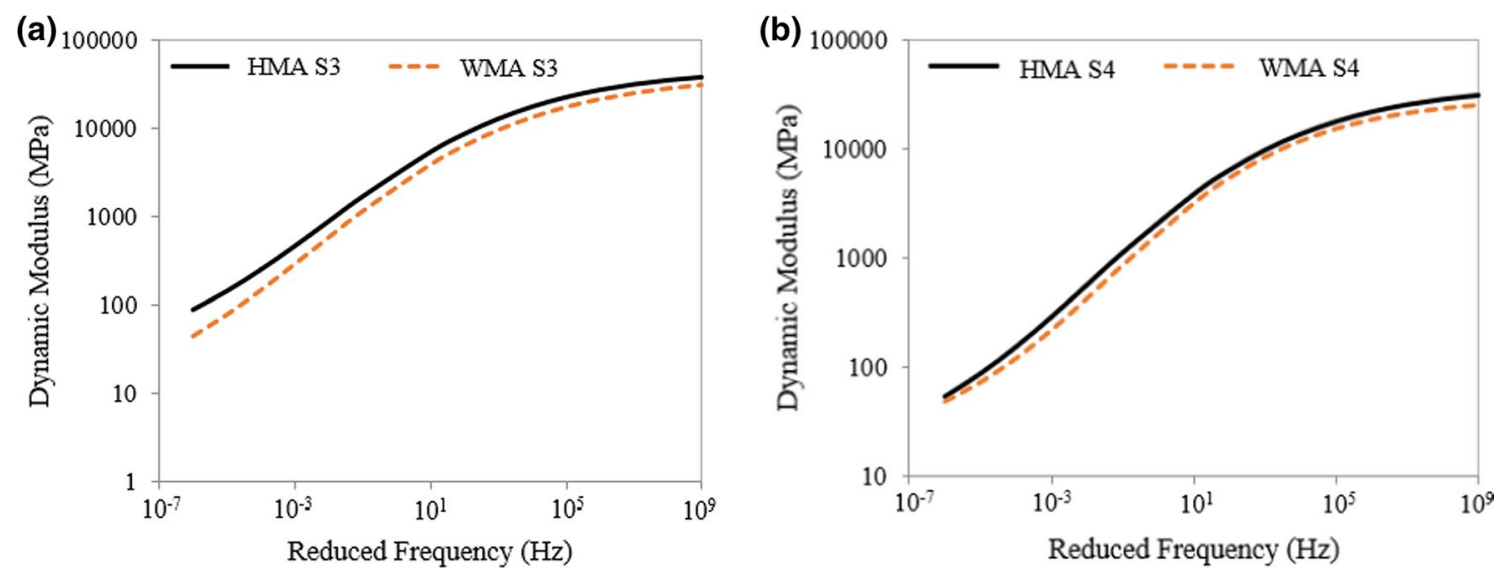

Fig. 1 Master curves at $21.1{ }^{\circ} \mathrm{C}$ reference temperature for a S3 mixes and b S4 mixes

The predicted dynamic modulus values found for HMA S4 and WMA S4 at $10^{-4} \mathrm{~Hz}$ reduced frequency were 151 $\mathrm{MPa}$ and $120 \mathrm{MPa}$, respectively. Therefore, WMA S3 and WMA $S 4$ are expected to show lower stiffness compared to HMA S3 and HMA S4, respectively. As noted previously, a lower degree of aging in WMA is expected to produce softer mixes compared to HMA [7, 17, 18]. Several other researchers have also reported lower dynamic modulus values for WMA compared to control HMA [13, 14, 28, 32]. A lower dynamic modulus is expected to cause more rutting in case of WMA [13]. It is also evident that both S3 mixes (HMA S3 and WMA S3) containing 25\% RAP had higher dynamic modulus values compared to S4 mixes (HMA S4 and WMA S4) containing 5\% RAP at $10^{-4} \mathrm{~Hz}$ reduced frequency. As reported by Ghabchi [13], higher RAP contents lead to stiffer mixes and higher dynamic modulus, which supports the results obtained in this study.

\section{Hamburg wheel tracking (HWT) test}

Figure 2a, b presents the HWT fitted graphs obtained in this study for S3 and S4 mixes, respectively. The fitted graphs were plotted based on the method proposed by Lu and Harvey [33]. It is evident from these figures that, for both cases, control HMA showed higher rutting resistance than foamed WMA containing identical amount of RAP. The test results indicated that, for similar numbers of wheel passes, higher rut depths were observed in foamed WMA samples compared to HMA samples, and this difference became increasingly dominant at higher numbers of passes. The rut depth at 10,000 wheel passes for HMA S3 and WMA S3 were found to be $2.2 \mathrm{~mm}$ and $4.3 \mathrm{~mm}$, respectively. Also, relatively a higher rut depth $(5.4 \mathrm{~mm})$ was observed for WMA S4 compared to HMA S4 $(2.7 \mathrm{~mm})$ at 10,000 wheel passes. Several rutting parameters, namely post-compaction deformation, creep slope, stripping slope, SIP and $\Delta \varepsilon_{10,000}^{v p}$ were
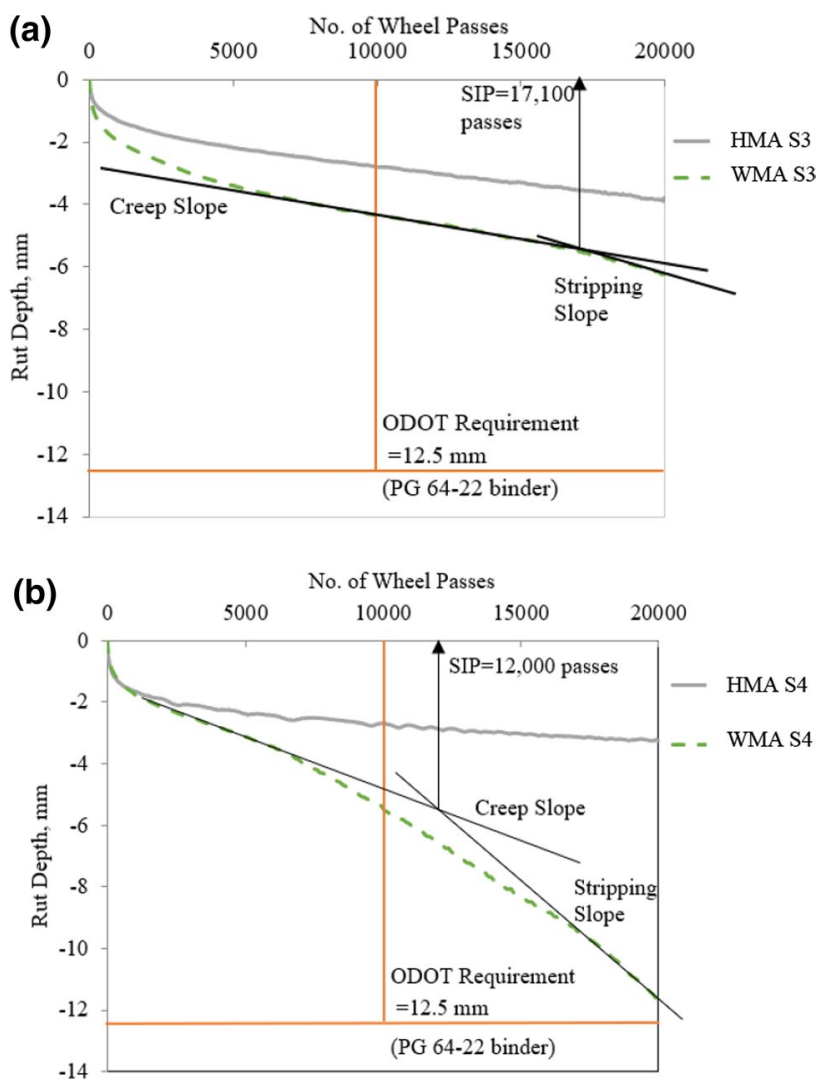

Fig. 2 Comparison of HWT graphs for a S3 mixes and b S4 mixes

determined from the HWT test results and are presented in Table 2. From Table 2, it is evident that WMA showed a higher post-compaction deformation compared to HMA. Furthermore, the inverse creep slope for WMA S3 was found to be 6667 passes $/ \mathrm{mm}$, whereas for HMA S3, the inverse creep slope was 10,000 passes $/ \mathrm{mm}$. Therefore, about two times higher rutting resistance during the creep phase was 
Table 2 Performance parameters obtained from HWT tests

\begin{tabular}{|c|c|c|c|c|c|c|c|}
\hline MIX ID & $\begin{array}{l}\text { Average } \% \\
\text { air voids }\end{array}$ & $\begin{array}{l}\text { Post } \\
\text { compaction } \\
(\mathrm{mm})\end{array}$ & $\begin{array}{l}\text { Creep slope } \\
(\mathrm{mm} / \text { passes })\end{array}$ & $\begin{array}{l}\text { Inverse creep } \\
\text { slope (passes/ } \\
\mathrm{mm} \text { ) }\end{array}$ & $\begin{array}{l}\text { Stripping inflec- } \\
\text { tion point (passes) }\end{array}$ & $\begin{array}{l}\text { Stripping slope } \\
(\mathrm{mm} / \text { passes })\end{array}$ & $\begin{array}{l}\text { Inverse stripping } \\
\text { slope (passes/ } \\
\mathrm{mm} \text { ) }\end{array}$ \\
\hline \multicolumn{8}{|c|}{ Conventional method } \\
\hline HMA S3 & 6.8 & 1.1 & 0.000100 & 10,000 & N/A & N/A & N/A \\
\hline WMA S3 & 6.8 & 2.0 & 0.000150 & 6667 & 17,100 & 0.000417 & 2400 \\
\hline HMA S4 & 6.9 & 1.7 & 0.000067 & 15,000 & N/A & N/A & N/A \\
\hline WMA S4 & 7.0 & 1.8 & 0.000339 & 2946 & 12,000 & 0.000756 & 1324 \\
\hline MIX ID & \multicolumn{3}{|c|}{ Average $\%$ air voids } & $\Delta \varepsilon_{10,000}^{v p}$ & \multicolumn{2}{|c|}{$\mathrm{LC}_{\mathrm{SN}}$} & $\mathrm{LC}_{\mathrm{ST}}$ \\
\hline \multicolumn{8}{|c|}{ Method outlined by Yin et al. [25] } \\
\hline HMA S3 & \multicolumn{3}{|c|}{6.8} & $1.08 \mathrm{E}-06$ & \multicolumn{2}{|c|}{$>20,000$} & - \\
\hline WMA S3 & \multicolumn{2}{|c|}{6.8} & & $1.74 \mathrm{E}-06$ & \multicolumn{2}{|c|}{$>20,000$} & - \\
\hline HMA S4 & \multicolumn{2}{|c|}{6.9} & & $0.59 \mathrm{E}-06$ & \multicolumn{2}{|c|}{$>20,000$} & - \\
\hline WMA S4 & \multicolumn{2}{|c|}{7.0} & & $3.33 \mathrm{E}-06$ & \multicolumn{2}{|c|}{4647} & 22,011 \\
\hline
\end{tabular}

observed for HMA S3 compared to WMA S3. Moreover, HMA S4 was found to exhibit about five times higher rutting resistance in the creep zone (15,000 passes/mm) compared to WMA S4 (2946 passes/mm). In addition, HMA S3 and HMA S4 were found to exhibit lower $\Delta \varepsilon_{10,000}^{v p}$ values compared to WMA S3 and WMA S4, respectively. Overall, foamed WMA is expected to show lower rutting resistance compared to their HMA counterparts. A similar observation for foamed WMA was reported by several other researchers $[1,4,6,9,20]$. This may be attributed to lower stiffness of WMA as indicated by dynamic modulus test results $[9,17]$.

From Table 2, it is evident that higher rutting resistance was exhibited by S3 mixes compared to S4 mixes. For WMA $\mathrm{S} 3$, rut depth observed at 10,000 wheel passes was $4.3 \mathrm{~mm}$, whereas at the same wheel passes, a rut depth of $5.4 \mathrm{~mm}$ was observed for WMA S4. Also, the inverse creep slopes for WMA S3 and WMA S4 were found to be 6667 passes $/ \mathrm{mm}$ and 2946 passes/mm, respectively, indicating higher rutting resistance for WMA S3 compared to WMA S4. A similar trend was observed for HMA S3 compared to HMA S4. The rut depths for HMA S3 and HMA S4 were found to be $2.2 \mathrm{~mm}$ and $2.7 \mathrm{~mm}$ at 10,000 wheel passes, respectively. The incorporation of higher percentage of RAP in S3 mixes ( $25 \%$ ) compared to $\mathrm{S} 4$ mixes $(5 \%)$ may have contributed to the increased rutting resistance. A similar increase in rutting resistance with an increase in RAP content was reported by several other researchers $[3,4,6,16,19]$.

\section{Flow number (FN) test}

Figure 3a, b shows the FN test results for S3 and S4 mixes, respectively. An asphalt mix with a higher $\mathrm{FN}$ value is expected to show higher resistance to rutting [6, 28]. For each mix type, three specimens were tested to check the repeatability of test results. The coefficients of variance (COVs) for HMA S3 and WMA S3 were found to be $4.6 \%$ and $19.5 \%$, respectively. Also, the COVs for HMA S4 and WMA S4 were found to be $14.2 \%$ and $21.7 \%$, respectively.

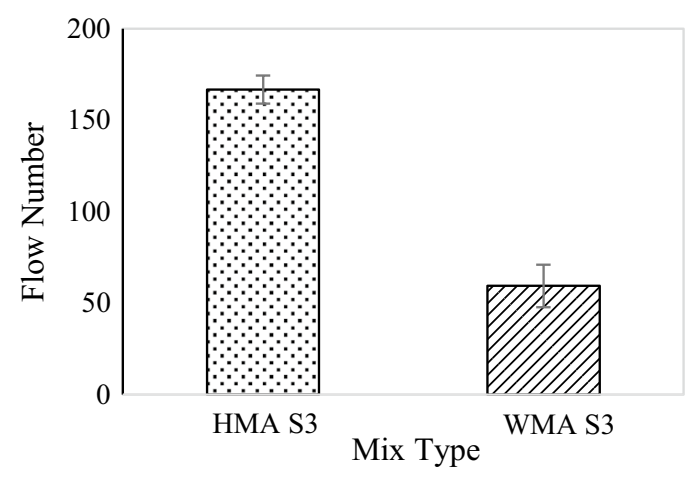

(a)

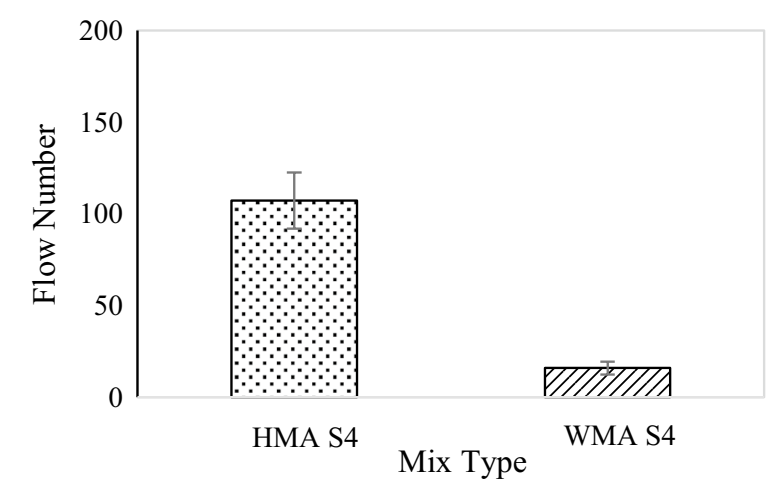

(b)

Fig. 3 Comparison of FN values for a S3 mixes and b S4 mixes 
The recommended COVs by AASHTO T 378 for mixes with NMAS of $19 \mathrm{~mm}$ and $12.5 \mathrm{~mm}$ are $58.5 \%$ and $43.1 \%$, respectively [22]. Therefore, the COV requirements were satisfied for both S3 and S4 mixes. Also, from Fig. 3 it was found that both WMA showed lower average FN values compared to their HMA counterparts. Therefore, higher COVs were observed for WMA mixes compared to HMA mixes. It is attributed to unit change in standard deviation causes higher COV for WMA mixes due to lower average values of FN. The average FN values for HMA S3 and WMA S3 were found to be 167 and 59, respectively. A similar trend was followed by $\mathrm{S} 4$ mixes. The average FN values for HMA S4 and WMA S4 were found to be 107 and 16, respectively. Therefore, lower resistance to rutting is expected for WMA compared to control HMA. A similar observation was reported by several other researchers [1, 4, 6, 9, 20]. Furthermore, S3 mixes were found to exhibit higher FN values compared to $\mathrm{S} 4$ mixes indicating higher rutting resistance for $\mathrm{S} 3$ mixes due to incorporation of high percentage of RAP $[3,4,6$, $16,19]$.

\section{Ranking of asphalt mixes based on rutting performance}

Table 3 presents the ranking of asphalt mixes based on various rutting parameters. The rating was conducted on a scale of 1-4, where 1 represents the best performing and 4 represents the worst performing asphalt mix. From HWT test data, rut depth at 10,000 wheel passes, inverse creep slope (passes $/ \mathrm{mm}$ ) and $\Delta \varepsilon_{10,000}^{v p}$ were considered for ranking the asphalt mixes. The rut depth at 10,000 wheel passes was considered based on ODOT's provision for mixes with a PG 64-22 binder (ODOT, 2011). Also, dynamic modulus value at $10^{-4} \mathrm{~Hz}$ reduced frequency and $21.1^{\circ} \mathrm{C}$ reference temperature was considered in ranking the rutting resistance of asphalt mixes. The ranking of asphalt mixes based on the FN value is included in Table 3 .

From Table 3 it is evident that foamed WMA was found to exhibit a lower rutting resistance than control HMA. Based on the rut depth, FN and dynamic modulus, HMA

Table 3 Ranking of asphalt mixes based on rutting resistance

\begin{tabular}{|c|c|c|c|c|c|}
\hline \multirow[t]{2}{*}{ Mix ID } & \multirow{2}{*}{$\begin{array}{l}\text { Dynamic } \\
\text { modulus }\end{array}$} & \multicolumn{3}{|c|}{ HWT indices } & \multirow[t]{2}{*}{ Average FN } \\
\hline & & $\begin{array}{l}\text { Rut depth } \\
\text { at } 10,000 \\
\text { wheel } \\
\text { passes } \\
(\mathrm{mm})\end{array}$ & $\begin{array}{l}\text { Inverse } \\
\text { creep } \\
\text { slope } \\
\text { (passes/ } \\
\text { mm) }\end{array}$ & $\Delta \varepsilon_{10,000}^{v p}$ & \\
\hline HMA S3 & 1 & 1 & 2 & 2 & 1 \\
\hline WMA S3 & 3 & 3 & 3 & 3 & 3 \\
\hline HMA S4 & 2 & 2 & 1 & 1 & 2 \\
\hline WMA S4 & 4 & 4 & 4 & 4 & 4 \\
\hline
\end{tabular}

S3 exhibited the highest resistance to rutting, followed by HMA S4, WMA S3, and WMA S4. However, HMA S4 showed the highest rutting resistance, followed by HMA S3, WMA S3, and WMA S4 when using inverse creep slope and $\Delta \varepsilon_{10,000}^{v p}$ for ranking. It was expected as the rutting rate in the creep zone was presented by both inverse creep slope and $\Delta \varepsilon_{10,000}^{v p}$. The finer aggregate gradation is believed to decrease the rutting potential for $\mathrm{S} 4$ mixes compared to $\mathrm{S} 3$ mixes. This is mainly attributed to a higher degree of aggregate segregation within the sample for coarser mixes [34-37]. The high RAP content, on the contrary, increases the rutting resistance of S3 mixes compared to $\mathrm{S} 4$ mixes. Therefore, these two opposing factors (aggregate gradation and RAP content) were found to rank HMA S3 and HMA S4 differently, while considering different parameters.

\section{Moisture-induced damage}

\section{Stripping infection point (SIP)}

Figure 2 shows that distinct SIPs for both WMA coarse (WMA S3) and fine (WMA S4) mixes were observed at about 17,100 and 12,000 wheel passes, respectively. However, no SIP was observed for the HMA. After SIPs, the rate of rut depth increased rapidly due to the intrusion of moisture in the specimen. For instance, the resistance to rutting reduced from 6667 passes $/ \mathrm{mm}$ to 2400 passes $/ \mathrm{mm}$ after the SIP for WMA S3 (Table 2). A similar trend was observed for WMA S4. Therefore, foamed WMA was found to exhibit more moisture-induced damage potential compared to control HMA. This may be attributed to partially dried aggregates at lower WMA mixing and compaction temperatures and injection of water vapor in the foamed WMA binder $[9,17,20]$.

The SIP for WMA S3 was observed at higher wheel passes $(17,100)$ compared to WMA S4 $(12,000)$. Also, the inverse stripping slope was higher for WMA S3 (2400 passes $/ \mathrm{mm}$ ) than WMA S4 (1324 passes/mm) indicating a higher resistance to stripping for WMA S3 due to an increase in RAP content. Also, based on the analysis of HWT results from the method proposed by Yin et al. [25], no $\mathrm{LC}_{\mathrm{SN}}$ was found within 20,000 wheel passes for WMA S3. However, WMA S4 was found to exhibit a $\mathrm{LC}_{\mathrm{SN}}$ value at 4647 wheel passes. Therefore, WMA S4 is likely to show a higher moisture-induced damage potential than WMA S3. The addition of aged binder from RAP is expected to have a positive effect on the moisture-induced damage resistance of asphalt mixes due to stronger bonding between RAP aggregate and binder. A similar finding for moisture-induced damage potential with increase in RAP content was reported by several other researchers $[5,14,15]$. 

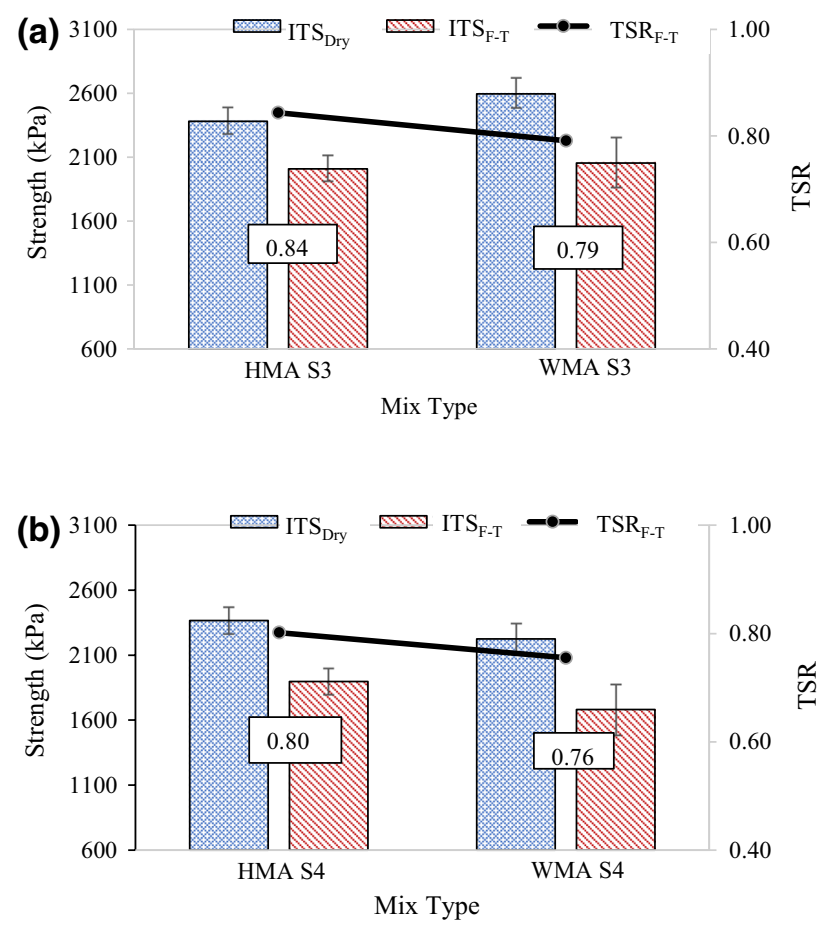

Fig. 4 Indirect tensile strength $\left(\mathrm{ITS}_{\text {dry }}\right.$ and $\left.\mathrm{ITS}_{\mathrm{F}-\mathrm{T}}\right)$ and TSR $\left(\mathrm{TSR}_{\mathrm{F}-\mathrm{T}}\right)$ values for a $\mathrm{S} 3$ mixes and b S4 mixes (AASHTO T 283 method)

\section{AASHTO T 283 method}

Figure 4 presents the ITS values of the dry (ITS $\left.{ }_{\text {dry }}\right)$ and freeze-thaw conditioned $\left(\right.$ ITS $\left._{\mathrm{F}-\mathrm{T}}\right)$ samples with TSR values $\left(\mathrm{TSR}_{\mathrm{F}-\mathrm{T}}\right)$ for all four mixes. The average $\mathrm{ITS}_{\mathrm{dry}}$ and ITS $_{\mathrm{F}-\mathrm{T}}$ values for HMA S3 were found to be $2381 \mathrm{kPa}$ and $2009 \mathrm{kPa}$ with standard deviations of $104 \mathrm{kPa}$ and $100 \mathrm{kPa}$, respectively. Also, the average ITS $_{\mathrm{dry}}$ and ITS $_{\mathrm{F}-\mathrm{T}}$ values for WMA S3 were found to be $2596 \mathrm{kPa}$ and $2054 \mathrm{kPa}$ with standard deviations of $117 \mathrm{kPa}$ and $194 \mathrm{kPa}$, respectively. Therefore, WMA S3 was found to exhibit a higher ITS compared to HMA S3 at both dry and moist conditions. However, the $\mathrm{TSR}_{\mathrm{F}-\mathrm{T}}$ value observed for WMA S3 was slightly lower (0.79) than HMA S3 (0.84). HMA S3 satisfied the ODOT specification (0.80) for $\mathrm{TSR}_{\mathrm{F}-\mathrm{T}}$, whereas WMA S3 did not satisfy the requirement by a small margin (0.01). A similar trend in the $\mathrm{TSR}_{\mathrm{F}-\mathrm{T}}$ value was observed for WMA S4 compared to control HMA S4 (Fig. 4b). The $\mathrm{TSR}_{\mathrm{F}-\mathrm{T}}$ value for WMA S4 was relatively lower (0.76) compared to HMA S4 (0.80). Therefore, WMA S4 did not satisfy the ODOT specification for moisture-induced damage (0.80), whereas HMA S4 satisfied the requirement. A higher moisture-induced damage potential for foamed WMA compared to HMA was reported by other researchers due to partially dried aggregates and incorporation of water in the foaming process $[9,17,20]$.
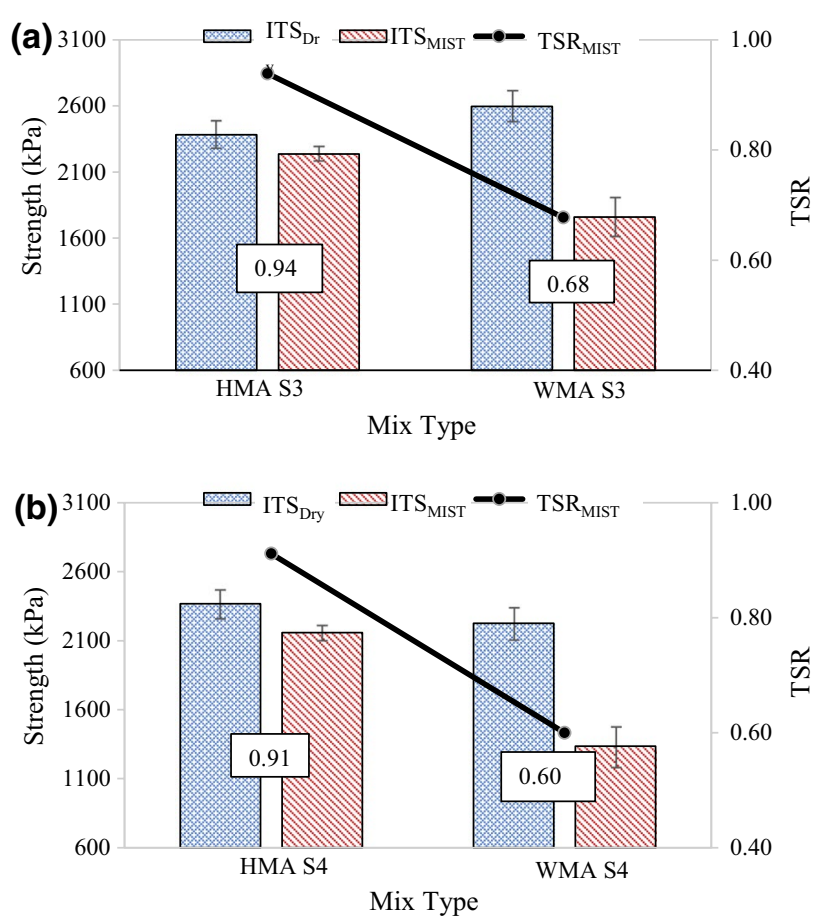

Fig. 5 Indirect tensile strength ( ITS $_{\text {dry }}$ and ITS $_{\text {MIST }}$ ) and TSR $_{\text {MIST }}$ values for a S3 mixes and b S4 mixes (MIST method)

\section{MIST conditioning}

Figure 5 presents the ITS values of the dry $\left(\operatorname{ITS}_{\text {dry }}\right)$ and MIST conditioned (ITS MIST $_{\text {) }}$ samples with TSR values $\left(\mathrm{TSR}_{\mathrm{MIST}}\right)$ for all four mixes. A significant reduction in ITS value was observed for both WMA S3 and WMA S4 after MIST conditioning. A lower $\mathrm{TSR}_{\mathrm{MIST}}$ value of 0.68 was observed for WMA S3 compared to control HMA S3

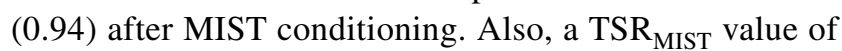
only 0.60 was observed for WMA S4, whereas HMA S4 exhibited a much higher $\mathrm{TSR}_{\mathrm{MIST}}$ value of 0.91 . Therefore, MIST conditioning followed a similar trend in screening the moisture-induced damage potential of asphalt mixes compared to SIP and TSR $\mathrm{F}_{\mathrm{T}}$. Furthermore, higher TSR $\mathrm{TIST}_{\mathrm{MIST}}$ values were found for $\mathrm{S} 3$ mixes compared to $\mathrm{S} 4$ mixes due to the increase in RAP amount [5, 14, 15].

In this study, MIST conditioning was found to screen the moisture-induced damage potential of WMA from HMA more distinctly compared to AASHTO T 283 conditioning method. In AASHTO T 283 method, environmental degradation of asphalt sample was simulated by one freeze-thaw cycle without considering traffic and cyclic pore pressure effects [22]. On the other hand, the generation and dissipation of pore water pressure in saturated pavement due to vehicular movement is simulated in the MIST conditioning process. In MIST, the stripping of asphalt mixes was caused by this generation of pore water pressure [38, 39]. 
Therefore, several researchers have suggested MIST technique in evaluating the moisture-induced damage potential of asphalt mixes [30, 40, 41].

\section{Ranking of asphalt mixes based on moisture susceptibility}

Table 4 shows the ranking of asphalt mixes using different parameters obtained from HWT and TSR test results. A similar ranking of moisture-induced damage potential for asphalt mixes was found based on different test parameters. No distinct SIP was observed for HMA in the HWT test results. Therefore, same rank was assigned for both HMA S3 and HMA S4. Also, $\mathrm{LC}_{\mathrm{SN}}$ values for HMA S3, WMA S3, and HMA S4 were found to be greater than 20,000 wheel passes and no $\mathrm{LC}_{\mathrm{ST}}$ values were found for these mixes. Therefore, these mixes were ranked as 1 based on $\mathrm{LC}_{\mathrm{SN}}$ and $\mathrm{LC}_{\mathrm{ST}}$ values. Furthermore, both TSR values followed a similar trend in ranking the asphalt mixes. Based on the TSR values, HMA S3 exhibited the highest resistance to moisture-induced damage, followed by HMA S4, WMA S3, and WMA S4. Therefore, foamed WMA technology is expected to produce higher moisture susceptible mixes due to the lowering of mixing and compaction temperatures. Ali et al. [20] suggested a longer drying period for aggregates in case of WMA to allow the entrapped water to escape. The moist aggregates increased the potential of moisture-induced damage for foamed WMA as inadequate aggregate coating may be resulted in presence of water [20]. Also, an increase in RAP content was found to be beneficial for moistureinduced damage resistance due to stronger bond between the aged binder and aggregates.

\section{Conclusions}

The rutting and moisture-induced damage potential of foamed WMA were evaluated and compared with those of control HMA having same gradations and containing the same amount of RAP. The dynamic modulus, HWT and FN tests were conducted to evaluate the rutting resistance. On the other hand, SIP, $\mathrm{LC}_{\mathrm{SN}}$, and $\mathrm{LC}_{\mathrm{ST}}$ from HWT test and TSR from two different conditioning methods were used to

Table 4 Ranking of asphalt mixes based on moisture-induced damage potential

\begin{tabular}{lllllll}
\hline Mix ID & \multicolumn{2}{l}{ HWT test } & & \multicolumn{2}{l}{ ITS test } \\
\cline { 2 - 3 } & SIP & $\mathrm{LC}_{\mathrm{SN}}$ & $\mathrm{LC}_{\mathrm{ST}}$ & & $\mathrm{TSR}_{\mathrm{F}-\mathrm{T}}$ & $\mathrm{TSR}_{\mathrm{MIST}}$ \\
\hline HMA S3 & 1 & 1 & 1 & & 1 \\
WMA S3 & 3 & 1 & 1 & 3 & 3 \\
HMA S4 & 1 & 1 & 1 & & 2 \\
WMA S4 & 4 & 4 & 4 & & 4 & 4 \\
\hline
\end{tabular}

evaluate the moisture-induced damage potential of asphalt mixes. Based on the results found in this study, the following conclusions can be drawn.

1. It was found that foamed WMA exhibited lower rutting resistance than HMA both having identical RAP contents. This was attributed to lower stiffness of WMA as indicated by dynamic modulus test results. Both fine and coarse WMA satisfied ODOT current provision for rut depth of $12.5 \mathrm{~mm}$ at 10,000 wheel passes in HWT test (ODOT, 2011).

2. The coarser mixes were found to exhibit higher rutting resistance than finer mixes due to increased RAP content. Incorporation of aged and stiffer binder from RAP was found to increase the stiffness of asphalt mixes, which resulted in higher rutting resistance.

3. A relatively low TSR value was observed for foamed WMA compared to HMA for both AASHTO T 283 and MIST conditioning methods, indicating higher moistureinduced damage potential for WMA. The MIST method was found to screen asphalt mixes more distinctly compared to the AASHTO T 283 method due to the application of cyclic loads during the conditioning process.

4. The foamed WMA technique was found to increase rutting potential and moisture-induced damage potential of asphalt mixes. On the contrary, addition of RAP was found to reduce rutting and moisture-induced damage potential. Therefore, a combination of foamed WMA technique with RAP may counteract each other's effects. Such counteracting effects should be taken into account in designing foamed WMA mixes.

\section{Limitations and recommendations}

In this study, only one type of a non-polymer-modified asphalt binder (PG 64-22) was considered for both mixes, namely HMA and foamed WMA containing RAP. However, the performance of foamed WMA prepared using different types of asphalt binders, such as polymer-modified binders, might be different from those observed in this study. Therefore, it is recommended that the effect of other binder types on performance characteristics of foamed WMA containing RAP be studied in future. Also, based on the previous studies conducted on foamed WMA technology and the current practice used by the local asphalt producers [1, 2], only one foaming water content was used in the preparation of foamed WMA. It is recommended that the effect of using different amounts of foaming water contents be examined in future studies. Furthermore, mixes containing up to $25 \%$ RAP were considered in this study. The effect of using a higher RAP content on properties of foamed WMA mixes should be studied further. 
Acknowledgements The authors would like to acknowledge the financial support provided by the Oklahoma Department of Transportation (ODOT) and Southern Plains Transportation Center (SPTC). The authors also want to thank the Silver Star Construction Co. for providing the necessary materials for this study. The support provided by the members of the Pavement Materials and Systems Group at OU are gratefully acknowledged. The authors are thankful to Dr. Amir Arshadi and Dr. Manik Barman for providing technical assistance throughout this study.

\section{Declarations}

Conflict of interest On behalf of all authors, the corresponding author states that there is no conflict of interest.

Open Access This article is licensed under a Creative Commons Attribution 4.0 International License, which permits use, sharing, adaptation, distribution and reproduction in any medium or format, as long as you give appropriate credit to the original author(s) and the source, provide a link to the Creative Commons licence, and indicate if changes were made. The images or other third party material in this article are included in the article's Creative Commons licence, unless indicated otherwise in a credit line to the material. If material is not included in the article's Creative Commons licence and your intended use is not permitted by statutory regulation or exceeds the permitted use, you will need to obtain permission directly from the copyright holder. To view a copy of this licence, visit http://creativecommons.org/licenses/by/4.0/.

\section{References}

1. Bonaquist RF (2011) Mix design practices for warm mix asphalt, vol 691. Transportation Research Board

2. Kheradmand B, Muniandy R, Hua LT, Yunus RB, Solouki A (2014) An overview of the emerging warm mix asphalt technology. Int J Pavement Eng 15(1):79-94

3. Dong F, Yu X, Xu B, Wang T (2017) Comparison of high temperature performance and microstructure for foamed WMA and HMA with RAP binder. Constr Build Mater 134:594-601

4. Guo N, You Z, Zhao Y, Tan Y, Diab A (2014) Laboratory performance of warm mix asphalt containing recycled asphalt mixtures. Constr Build Mater 64:141-149

5. Zhao S, Huang B, Shu X, Jia X, Woods M (2012) Laboratory performance evaluation of warm-mix asphalt containing high percentages of reclaimed asphalt pavement. Transp Res Rec 2294(1):98-105

6. Zhao S, Huang B, Shu X, Woods M (2013) Comparative evaluation of warm mix asphalt containing high percentages of reclaimed asphalt pavement. Constr Build Mater 44:92-100

7. Alhasan AA, Abbas AR, Nazzal M, Dessouky S, Ali A, Kim S-S, Powers D (2014) Low-temperature characterization of foamed warm-mix asphalt produced by water injection. Transp Res Rec 2445(1):1-11

8. Jones W (2004) Warm mix asphalt-a state-of-the-art review. Australian Asphalt Pavement Association Advisory Note 17

9. Prowell BD, Hurley GC, Crews E (2007) Field performance of warm-mix asphalt at national center for asphalt technology test track. Transp Res Rec 1998(1):96-102

10. Rubio MC, Martínez G, Baena L, Moreno F (2012) Warm mix asphalt: an overview. J Clean Prod 24:76-84

11. Kristjansdottir O (2006) Warm mix asphalt for cold weather paving. In: University of Washington Seattle
12. Al-Qadi IL, Ozer H, Lambros J, El Khatib A, Singhvi P, Khan T, Rivera-Perez J, Doll B (2015) Testing protocols to ensure performance of high asphalt binder replacement mixes using RAP and RAS. In: Illinois Center for Transportation/Illinois Department of Transportation

13. Ghabchi R (2014) Laboratory characterization of recycled and warm mix asphalt for enhanced pavement applications

14. Shu X, Huang B, Shrum ED, Jia X (2012) Laboratory evaluation of moisture susceptibility of foamed warm mix asphalt containing high percentages of RAP. Constr Build Mater 35:125-130

15. Hill B, Behnia B, Buttlar WG, Reis H (2012) Evaluation of warm mix asphalt mixtures containing reclaimed asphalt pavement through mechanical performance tests and an acoustic emission approach. J Mater Civ Eng 25(12):1887-1897

16. Shu X, Huang B, Vukosavljevic D (2008) Laboratory evaluation of fatigue characteristics of recycled asphalt mixture. Constr Build Mater 22(7):1323-1330

17. Hurley GC, Prowell BD (2006) Evaluation of potential processes for use in warm mix asphalt. J Assoc Asphalt Paving Technol 75:41-90

18. Malladi H (2015) Investigation of warm mix asphalt concrete mixtures with recycled asphalt pavement material

19. Hong F, Chen D-H, Mikhail MM (2010) Long-term performance evaluation of recycled asphalt pavement results from Texas: pavement studies category 5 sections from the long-term pavement performance program. Transp Res Rec 2180(1):58-66

20. Ali A, Abbas A, Nazzal M, Alhasan A, Roy A, Powers D (2013) Effect of temperature reduction, foaming water content, and aggregate moisture content on performance of foamed warm mix asphalt. Constr Build Mater 48:1058-1066

21. Xu S, Xiao F, Amirkhanian S, Singh D (2017) Moisture characteristics of mixtures with warm mix asphalt technologies-a review. Constr Build Mater 142:148-161

22. AASHTO (2018) Standard specifications for transportation materials and methods and sampling and testing, Washington, DC

23. Chehab GR, O'Quinn E, Richard Kim Y (2000) Specimen geometry study for direct tension test based on mechanical tests and air void variation in asphalt concrete specimens compacted by superpave gyratory compactor. Transp Res Rec 1723(1):125-132

24. Singh D (2011) A laboratory investigation and modeling of dynamic modulus of asphalt mixes for pavement applications. The University of Oklahoma

25. Yin F, Arambula E, Lytton R, Martin AE, Cucalon LG (2014) Novel method for moisture susceptibility and rutting evaluation using Hamburg wheel tracking test. Transp Res Rec 2446(1):1-7

26. Yildirim Y, Kennedy TW (2002) Hamburg wheel tracking device results on plant and field cores produced mixtures. In: Citeseer

27. Roberts FL, Kandhal PS, Brown ER, Lee D-Y, Kennedy TW (1991) Hot mix asphalt materials, mixture design and construction

28. Copeland A, D'Angelo J, Dongre R, Belagutti S, Sholar G (2010) Field evaluation of high reclaimed asphalt pavementwarm-mix asphalt project in Florida: case study. Transp Res Rec 2179(1):93-101

29. Kim Y-R, Zhang J, Ban H (2012) Moisture damage characterization of warm-mix asphalt mixtures based on laboratory-field evaluation. Constr Build Mater 31:204-211

30. Chen X, Huang B (2008) Evaluation of moisture damage in hot mix asphalt using simple performance and superpave indirect tensile tests. Constr Build Mater 22(9):1950-1962

31. ASTM D (2016) American Society for Testing and Materials (ASTM), Philadelphia, USA

32. Rahman MA, Zaman M, Ali SA, Ghabchi R, Ghos S (2021) Evaluation of mix design volumetrics and cracking potential of foamed warm mix asphalt (WMA) containing reclaimed asphalt pavement (RAP). Int J Pavement Eng 1-13 
33. Lu Q, Harvey JT (2006) Evaluation of Hamburg wheel-tracking device test with laboratory and field performance data. Transp Res Rec 1970(1):25-44

34. Sebaaly PE, Hand AJ, McNamara WM, Weitzel D, Epps JA (2004) Field and laboratory performance of superpave mixtures in Nevada. Transp Res Rec 1891(1):76-84

35. Golalipour A, Jamshidi E, Niazi Y, Afsharikia Z, Khadem M (2012) Effect of aggregate gradation on rutting of asphalt pavements. Proc Soc Behav Sci 53:440-449

36. Krutz NC, Sebaaly PE (1993) The effects of aggregate gradation on permanent deformation of asphalt concrete. J Assoc Asphalt Pav Technol 62

37. Uge P, Van de Loo P (1974) Permanent deformation of asphalt mixes. Shell Research Laboratories
38. Kutay ME, Aydilek AH (2007) Dynamic effects on moisture transport in asphalt concrete. J Transp Eng 133(7):406-414

39. Jiang W-H, Zhang X-N, Li Z (2013) Simulation test of the dynamic water pressure of asphalt concrete. J Highway Transp Res Dev (Eng Edn) 7(1):23-27

40. Mallick RB, Pelland R, Hugo F (2005) Use of accelerated loading equipment for determination of long term moisture susceptibility of hot mix asphalt. Int J Pave Eng 6(2):125-136

41. Weldegiorgis MT, Tarefder RA (2014) Towards a mechanistic understanding of moisture damage in asphalt concrete. J Mater Civ Eng 27(3):04014128 